\title{
Manejar las emociones, factor importante en el mejoramiento de la calidad de vida*
}

\section{Handle the emotions- important factor in the mejoramiento of the quality of life Manejar emocione-las- factor importante no mejoramiento da qualidade de vida}

Revista LOGOS CIENCIA \& TECNOLOGÍA ISSN 2145-549X, Vol 4. No. 1, Julio - Diciembre, 2012, pp. 58-67

\section{Resumen}

En este escrito se resaltarán algunos de los puntos más importantes de la obra de Daniel Goleman, reconocido psicólogo y autor de varios libros, entre ellos "La Inteligencia Emocional", con el ánimo de encaminar actividades hacia el establecimiento de hábitos y el fortalecimiento de habilidades emocionales, que conlleven a una sana convivencia y que promueva el mejoramiento de la calidad de vida de cada individuo. Entendiendo esta como el "Bien Estar o Estar Bien" en términos de tranquilidad, paz interior y óptima forma de relacionarnos en sociedad.

Fecha de Recepción: 16 de febrero de 2012

Fecha de Aceptación: 25 de abril de 2012

* Este artículo es producto del Proyecto presentado ante el Centro Agroecológico y Empresarial en Fusagasugá.

** Psicóloga, Universidad Católica de Colombia. Correo canomusa71@misena.edu.co

*** Psicóloga, Universidad UNAD. Correo: marce.z@misena. edu.co
Palabras clave: Emoción, Estados de Ánimo, Inteligencia Emocional, Empatía, Valores, Altruismo, Asertividad Emocional, Calidad de Vida.

\begin{abstract}
In this paper will highlight some of the highlights of the work of Daniel Goleman, renowned psychologist and author of several books, including" Emotional Intelligence", with the aim of directing activities towards establishing and strengthening habits emotional skills, that lead to healthy living and to promote improved quality of life of each individual. Understanding this as the "Be Good or Be Good" in terms of tranquility, inner peace and optimal way of relating to society.
\end{abstract}

Key Words: Emotion, Moods, Emotional intelligence, Empathy, Values, Altruism, Assertiveness, Emotional, Quality of Life

\section{Resumo}

Neste escrito ressaltassem-se alguns dos pontos mais importantes da obra de Daniel Goleman, re- 
conhecido psicólogo e autor de vários livros, entre eles "A Inteligência Emocional ", com o ânimo de encaminhar actividades para o estabelecimento de hábitos e o fortalecimiento de habilidades emocionais, que impliquem a uma sã convivência e que promova o mejoramiento da qualidade de vida da cada indivíduo. Entendendo esta como o "Bem Estar ou Estar Bem" em termos de tranquilidade, paz interior e optima forma de relacionar-nos em sociedade.

Palavras chave: Emoção, Estados de Ânimo, Inteligência Emocional, Empatía, Valores, Altruismo, Asertividad Emocional, Qualidade de Vida

\section{INTRODUCCIÓN}

"En su sentido literal, la emoción es cualquier agitación y trastorno de la mente, el sentimiento, la pasión; cualquier estado mental vehemente o excitado"1.

Sin embargo Goleman se refiere a ella como "un sentimiento y sus pensamientos característicos a estados psicológicos y biológicos y a una variedad de tendencias e impulsos a actuar" (1995, p. 331).

Desde una perspectiva más vivencial las emociones son alteraciones súbitas y rápidas que experimentamos desde nuestro estado de ánimo, la mayoría de veces por ideas, recuerdos o circunstancias. Algunas de las más comunes son: la ira, la tristeza, el temor, el placer, la sorpresa, el disgusto, la vergüenza y el amor, aunque este último es considerado también un sentimiento. Todas ellas son muestras de sensaciones fugaces, que vienen y van, como ya dijimos, de acuerdo al estado de ánimo en el que nos encontremos; sin embargo, de ellas se desprenden los sentimientos que son sensaciones más duraderas y perdurables en términos de temporalidad y a través de diversas circunstancias.

Lamentablemente, la mayoría de las emociones se consideran negativas, ya que causan perjuicio no

De acuerdo con el Oxford English Dictionary, publicado por la editorial Oxford University Press. Actualización 2005. solo a la salud mental, sino también a la salud física y espiritual del individuo.

Podemos evidenciar que la ira, el enojo, la irritación, el odio y el resentimiento, son emociones negativas que experimentamos de acuerdo a nuestro estado de ánimo, es decir que si estamos molestos con alguien o por algo, o en ambas circunstancias, reaccionamos demostrando las mismas; sin embargo, dichas emociones juegan un papel muy dañino en la vida de los seres humanos, ya que debido a ellas realizamos actos de los cuales después nos arrepentimos y casi nunca podemos reparar. Además terminamos siendo seres amargados, aislados y alejados del mundo y de todo lo bello que él tiene.

Cada uno de estos estados juega un papel primordial en la realidad social que estamos viviendo, ya que al dejarnos llevar por estas emociones negativas, caemos en injusticias, violencias, agresiones, intolerancias y demás aspectos que fundamentan los antivalores que están evidenciando la crisis por la cual atraviesa nuestra sociedad. Cualquier cosa que nos moleste, que nos perjudique o que simplemente no nos guste, genera este tipo de emociones y conlleva a realizar actos bárbaros, como lo es derramar ácido en la cara o cuerpo de alguien, agredirlo, físi$\mathrm{ca}$, verbal o psicológicamente, entre otras. Sin embargo, algunas de estas actuaciones las podríamos catalogar como patológicas, ya que no es normal o común que las personas reaccionen de esta forma, haciendo daño físico al individuo o individuos causantes de su frustración o dolor, por lo general, a pesar de que a nuestra mente lleguen pensamientos de infringir un daño inmediato, al pasar unos instantes reflexionamos y actuamos de acuerdo a nuestros principios éticos y valores inculcados; y dichos instintos bárbaros se quedan en nuestra imaginación y hacen parte de las fantasías que quedarán en nuestro subconsciente, y que nunca llevaremos al plano de lo real y físico.

Cuando lo anteriormente planteado ocurre, podemos decir que tenemos un dominio de nosotros mismos y nuestras reacciones, es decir tenemos Autocontrol, entendido como la facultad de frenar nuestros impulsos y pensar antes de actuar, lo que se considera una actuación bastante inteligente. 
Gardner (1983) habla sobre:

La teoría de las "inteligencias múltiples" como aquellas capacidades distintas e independientes que tenemos todos los seres humanos, para resolver problemas o elaborar productos que sean valiosos en una o más culturas, en cada una de las áreas que las atañen (Lógico-matemática, Musical, Corporal Cinética, Lingüística, Espacial, Naturalista, Intrapersonal e Interpersonal).

De acuerdo con esta teoría, todos los seres humanos podemos desarrollar diversas habilidades en diferentes campos, adicionales a los que abarca la educación tradicional, y a través de los cuales se puede determinar nuestro nivel de inteligencia.

Armstrong, (2000) sugiere:

Que las escuelas y la cultura centran la mayor parte de su atención en las inteligencias lingüística y lógico-matemática. Sin embargo, dice que también se debe poner atención en las personas con otros tipos de inteligencias: artistas, arquitectos, músicos, cuidadores, diseñadores de moda, bailarines $y$ otras personas que hacen del mundo un lugar maravilloso para vivir.

De acuerdo con lo anterior y visto en la práctica, nuestro sistema educativo gira alrededor de estas dos clases de inteligencia: La lógico Matemática y la Lingüística, ya que siempre nos ha inculcado que debemos sobresalir en estas áreas, para lograr mejores resultados en nuestra vida profesional. Sin embargo, actualmente, gracias a la teoría planteada por el doctor Gardner, son varias las instituciones de tipo privado, que están incursionando en nuevos modelos pedagógicos personalizados, que permitan al estudiante desarrollar sus capacidades y habilidades particulares, sin "obligarles" a absorber una serie de conocimientos que tal vez nunca emplearán en su vida laboral o profesional.

En la educación media encontramos la formación por competencias, por medio de la cual se adquieren los conocimientos teóricos básicos, haciendo especial énfasis en la práctica de los procedimientos y funciones específicas frente a una labor dada, lo que ha permitido una mayor eficacia y eficiencia en el desempeño laboral, ya que como se dice popularmente: hacer se aprende haciendo".

Sin embargo, no podemos olvidar que a pesar de que se tengan habilidades extraordinarias y amplios conocimientos sobre algún campo aplicado a las profesiones, se hace necesario y primordial aprender a resolver nuestros propios problemas y conflictos a nivel personal y emocional.

Goleman (1995) plantea:

"La inteligencia se define como la capacidad de resolver problemas y de crear conductas que tienen un valor cultural, por lo tanto la inteligencia emocional $^{2}$ será la capacidad de resolver problemas de carácter emocional, que involucra el control de los impulsos que sentimos ante determinada situación".

Así que no solamente debemos ser inteligentes en la realización de tareas cotidianas, sino que también debemos aprender a solucionar nuestros propios conflictos internos y externos, entendiendo $y$ solucionando los casos particulares y tomando los correctivos necesarios para lograr una mejor adaptabilidad al medio y por lo tanto una vida emocional más sana. De nuestro actuar emocional depende mucho el desarrollo de nuestras habilidades sociales y el éxito o fracaso que proyectemos durante nuestra convivencia en sociedad.

Howard Gardner (1983) formuló:

El concepto de "inteligencias múltiples", donde se incluyen tanto una inteligencia "interpersonal" (externas o de relación) como una "intrapersonal" (internas o de autoconocimiento), al primer grupo pertenecen tres habilidades: la autoconciencia o habilidad para saber que está pasando en nuestro cuerpo y qué estamos sintiendo; el control emocional, que permite regular la manifestación de una emoción y/o modificar un estado anímico y

2 El término inteligencia emocional es atribuido en un principio a John Mayer y Peter Salovey en la década de 1980, en sus estudios publicados sobre la interacción entre emoción y la cognición. 
su exteriorización; y, finalmente la capacidad de auto motivarse y motivar a los demás. Al segundo grupo pertenecen dos habilidades: la empatía, cuyo origen se sitúa en mecanismos neuronales básicos desarrollados a lo largo de la evolución ${ }^{3}$, pero que para efectos de este escrito definimos como la capacidad de entender qué están sintiendo otras personas, ver cuestiones y situaciones desde su perspectiva y, las habilidades sociales que son aquellas habilidades que rodean la popularidad, el liderazgo y la eficacia interpersonal, y que pueden ser usadas para persuadir, dirigir, negociar y resolver disputas para la cooperación y el trabajo en equipo. Ambas asociadas con el concepto de inteligencia emocional.

Gardner afirmó también "que la inteligencia de una persona varía de acuerdo con cómo es inteligente y no cuan inteligente es". (1983, p. 335). Con esto podemos decir que la inteligencia emocional no es algo nuevo y el cociente de inteligencia o coeficiente Intelectual $(\mathrm{Cl})^{4}$ no es la única medida de la inteligencia humana. La inteligencia emocional se aplica a todos los seres humanos y en todas las etapas, en todas las profesiones y condiciones sociales.

En términos más simples podemos decir que la inteligencia emocional se refiere al reconocimiento y comprensión tanto de nuestras emociones como las de los demás, y enfrentar de manera efectiva su impacto usando enfoques y acciones apropiadas.

Goleman (1995) maneja conceptos como:

Conocimiento de uno mismo, manejo emocional, auto motivación, empatía, manejo de las relaciones, habilidades de comunicación y estilo personal. Describe a las personas emocionalmente expertas como aquellas que conocen y manejan bien sus propios sentimientos y que tratan en forma efectiva con los sentimientos de otras personas.

3 Cf. Frans B. M. de Waal, "La empatía en los animales», Mente y Cerebro, 38, 2009, págs. 20-27.

4 Diccionario de la Real Academia Española, Avance de la $23^{a}$ edición, cociente intelectual.
Cabe anotar que quien llega a conocerse bien, es capaz de controlar sus propias emociones, motivarse a sí mismo y recurrir a la empatía para lograr comprender, entender y tolerar las actuaciones de los demás, aunque no las comparta o no esté de acuerdo con ellas.

Goleman (1995) explica que:

El éxito de una persona no depende del intelecto o de estudios académicos, si no de su inteligencia emocional, que según el autor es la capacidad de reconocer los sentimientos propios y los de los demás, para así manejar bien las emociones y tener relaciones más productivas con quienes nos rodean, y haciendo hincapié que no nacemos con inteligencia emocional sino que nosotros mismos la podemos crear, alimentar y fortalecer a través de nuestros conocimientos. También la podemos apreciar en nuestra capacidad de hacer las cosas, nuestras habilidades, desempeñarnos bien en las situaciones de la vida cotidiana, trabajo, relaciones de pareja, familia, estudio y demás.

Una de las herramientas necesarias para lograr el desarrollo de la inteligencia emocional es la automotivación, entendida como es la capacidad para motivarnos a nosotros mismos, el dominio que tenemos sobre nuestros sentimientos y emociones, tenemos que luchar para mantener un control sobre las situaciones que se nos presentan, las emociones son importantes para ejercer el uso de nuestra razón y son las que marcan el rumbo de nuestras decisiones de manera constante.

Contamos con dos tipos de inteligencia, la inteligencia emocional y la inteligencia racional, en la inteligencia emocional somos capaces de sentir todo lo que vivimos; situaciones que van desde una profunda y plena alegría hasta eventos de una tristeza inmensa, es así que las decisiones que tomamos se basan en estos sentimientos. Por otra parte, en la inteligencia racional todos los individuos activamos las habilidades propias de nuestro pensamiento y casi siempre nos inclinamos por las decisiones que creemos que son más pertinentes. Es de suma importancia señalar que existen personas con una capacidad extraordinaria y que estas son muy per- 
ceptibles y comprensivas con los sentimientos de los demás. Estas personas demuestran que tienen habilidades fuera de lo común y las plasman siendo líderes en los diferentes tipos de sectores sociales en donde se desenvuelven.

Si más personas
replicáramos buenas
actitudes y hábitos
de cordialidad, de
seguro lograríamos
transformar
nuestro entorno
de hostilidad,
indiferencia y
agresividad en
un ambiente de
amabilidad que
abriría y suavizaría
nuestros corazones
y los de todas las
personas a nuestro
alrededor.

Desde un punto de vista lógico, cualquier individuo a medida que va creciendo en edad, madurez y experiencia, también debe crecer en el desarrollo de sus sentimientos. Es así, como en esta época de grandes y constantes cambios en todas las esferas de la sociedad, se les exige a los individuos estar preparados para enfrentar nuevos y diversos desafíos como los que acarrea principalmente el efecto de la globalización, la cual impone todo tipo de exigencias a la sociedad en la que vivimos, cambiando la manera de percibir los valores y en las organizaciones ocasionando riesgo a su fuerza laboral. Por tal motivo, debemos aprender a manejar nuestras emociones y sentimientos, y propender a una completa armonía con nuestro intelecto, para poder responder al mundo de una manera adecuada e inteligente, en la cual podamos obtener los resultados esperados para nosotros y para quienes nos rodean.

Por todo lo anterior, se hace necesario e indispensable desarrollar habilidades emocionales que nos permitan llegar al autocontrol de dichas emociones, para mejorar nuestras relaciones interpersonales y cultivar nuestra inteligencia emocional ${ }^{5}$.

5 Gardner (1983), afirma que la inteligencia emocional constituye un conjunto de destrezas emocionales, una forma de interactuar con el mundo y que tiene muy en cuenta los sentimientos. Implica una serie de habilidades emocionales como la autoconfianza, la empatía, la perseverancia, la autoconciencia y el autocontrol.
A este respecto López y Arango (2002) afirman que:

La inteligencia emocional es la capacidad de dominar las emociones y configurar rasgos de carácter como la autodisciplina, la compasión y el altruismo. Consiste en saber reconocer lo que se siente, controlar las respuestas emocionales, aprender a automotivarse y a entusiasmarse con lo que se quiere. Definir y conseguir metas, afrontar la vida con confianza y optimismo, comprender los sentimientos de los demás y relacionarse armoniosamente con ellos. (p. 198).

A veces encontramos personas llenas de energía positiva, que tan solo con un saludo o una sonrisa, logran cambiar nuestra cara larga y hasta amargada, por una más amable y cordial, pues como dice un antiguo proverbio chino "No eres responsable de la cara que tienes, eres responsable de la cara que pones", todos los rostros del mundo son espejos que reflejan lo que se lleva por dentro, el reflejo de los gestos y acciones es lo que proyectamos a los demás.

Si más personas replicáramos buenas actitudes y hábitos de cordialidad, de seguro lograríamos transformar nuestro entorno de hostilidad, indiferencia y agresividad en un ambiente de amabilidad que abriría y suavizaría nuestros corazones y los de todas las personas a nuestro alrededor.

En los últimos tiempos la "enfermedad emocional", causada por el inadecuado manejo de las emociones, se ha propagado como virus letal, dando como resultado el constante aumento de enfermedades depresivas, maltratos y violencia intrafamiliar, niños $y$ adolescentes que pasan a ser criminales en potencia con el manejo de las armas y el consumo de drogas, el estrés, etc.

Goleman (1995) afirma:

"Durante las dos décadas anteriores se han realizado avances científicos en la investigación del funcionamiento del cerebro humano a nivel neurobiológico, que nos permite comprender más claramente cómo los centros de la emoción del cerebro nos provocan ira o llanto, y cómo partes más primitivas del mismo, nos mueven a hacer la 
guerra y también el amor, están canalizadas para bien o para mal". (p. 15).

Hasta ahora han surgido muchos escritos con énfasis en la superación personal y la autoayuda, basados en algunos casos clínicos pero sin la fundamentación científica necesaria. Además, se creía que el cociente intelectual era un factor genético, que no podía ser modificado por las experiencias de vida y que nuestro destino estaba fijado en gran medida por estas aptitudes.

Goleman (1995) plantea los siguientes interrogantes:

¿Qué podemos cambiar que ayude a nuestros hijos a tener mejor suerte en la vida? ¿Qué factores entran en juego, por ejemplo, cuando las personas que tienen un elevado cociente intelectual tienen dificultades y las que tienen un cociente intelectual modesto, se desempeñan sorprendentemente bien? Afirma que la diferencia suele estar en las habilidades que denomina "Inteligencia Emocional", que incluye el autodominio, el celo, la persistencia y la capacidad de automotivación, estas habilidades pueden ser enseñadas, mejorando las posibilidades de utilizar el potencial intelectual que la genética les haya brindado.

Actualmente, nuestra sociedad se debate en el egoísmo, la violencia y la ruindad espiritual, lo que afecta enormemente nuestra calidad de vida comunitaria y por ende la individual.

La importancia de la inteligencia emocional gira en torno a la relación que existe entre sentimiento, carácter e instintos morales. Las evidencias apuntan a que las posturas éticas fundamentales en la vida, surgen de capacidades emocionales latentes. Los que se dejan llevar por los impulsos como instrumentos de las emociones, no presentan rasgos de autodominio y por tanto padecen una deficiencia moral, entendida como la incapacidad de controlar el impulso como base de voluntad y carácter.

Cuando una persona se llena de ira ante una situación determinada, justifica su alteración con una serie de motivos que generalmente resultan erróneos, pero que logran alterarla tanto que se vuelve implacable y violenta y se hace imposible razonar con ella, su pensamientos giran en torno a la venganza y la represalia y no le importan las posibles consecuencias de sus actos. Todo este caos emocional hace que se pierda la perspectiva y se olviden los derechos, sentimientos y emociones de quien se ha vuelto el objeto de nuestra ira, por lo tanto no nos preocupa lo que este pueda sentir o sufrir, es decir carecemos de la empatía necesaria "ponernos en sus zapatos" y entender las razones de su comportamiento.

Goleman (1995) afirma:

La raíz del altruismo se encuentra en la empatía, la capacidad de interpretar las emociones de los demás; si no se siente la necesidad o la desesperación del otro, no existe preocupación, es decir somos indiferentes ante su situación, incapaces de sentir compasión.

Pero la empatía se construye sobre la conciencia de uno mismo, entre más nos conozcamos y aprendamos a identificar nuestras emociones, más habilidades adquirimos para la interpretación de los sentimientos y emociones de otros. Cuando logramos sentir lo que el otro siente, nos preocupamos por él y por ende no propiciamos ninguna acción que pueda causarle daño. Si este valor ha sido adquirido, interiorizado y aplicado en nuestro diario vivir, seremos capaces de practicar el altruismo que en su sentido más simple es "hacer el bien sin mirar a quien", pero que si lo llevamos a la aplicabilidad de nuestras creencias religiosas, notaremos que se fundamenta en los mandamientos de la ley de Dios: "Amarás a Dios sobre todas las cosas y al prójimo como a ti mismo" y en el valor de la compasión, que Cristo nos enseñó.

Lo rescatable de todo esto es que no solo la experiencia, sino todos los datos neuro-biológicos hallados a través de la ciencia, abren un sinnúmero de posibilidades para crear, mantener y fortalecer hábitos emocionales favorables en nuestros hijos y si se quiere en nuestros jóvenes, para cultivar su inteligencia emocional y así poder controlar de alguna manera sus impulsos emocionales, practicar la empatía interpretando y entendiendo la postura del otro y llegar a 
tener la habilidad planteada en el Desafío Aristotélico: "Cualquiera puede ponerse furioso...eso es fácil. Pero estar furioso con la persona correcta, en la intensidad correcta, en el momento correcto, por el motivo correcto y de la forma correcta... eso no es fácil". Es decir, en la práctica de la asertividad emocional está el secreto para el manejo de las emociones. Lograr dicha asertividad depende también de una adecuada comunicación, la cual se puede lograr cuando escuchamos un mensaje o una información y podemos asimilarla e interiorizarla, siempre y cuando eso que escuchamos sea significativo para nosotros. Pero, ¿Qué es lo que hace que una información o mensaje tenga significado (o sea significativo para una persona? Consideramos que darle significado a algo que expresamos o transmitimos, depende del sentido que le demos, es decir, que el lenguaje empleado, no solo sea claro, sencillo, y asertivo, sino que además le apliquemos emocionalidad a las palabras.

Adicionalmente,
debemos llevar
todos nuestros
esfuerzos a rescatar
la tolerancia, la
solidaridad, la
compasión, el
verdadero amor filial
y la empatía.

Cuando queremos que la información transmitida genere un cambio en las personas que la escuchan (alumnos, aprendices, discentes o receptores), debemos transmitir un componente que "toque" los sentimientos de quienes la escuchan para que así sea interiorizada y permanezca en su mente y su subcons-

ciente, e igualmente genere algún tipo de respuesta proactiva.

Por otra parte, lo que refuerza el entendimiento es la capacidad de reflexión y si esta se da simultáneamente al recibir la información, se puede generar un enriquecedor "feed back", que involucrará tanto al emisor como al receptor, lo que ayudará a la participación activa de todos los involucrados en el proceso comunicativo, dándole una dinámica enriquecedora y muy productiva para el aprendizaje.

En la construcción de nuestra propia realización como "Seres humanos", es indispensable saber y recordar de dónde venimos, quiénes somos y para dónde vamos; es por ello que los ideales y metas fijados siempre deberán estar en función de estas tres dimensiones del ser, enmarcadas dentro de lo que llamamos "Proyecto de Vida".

Y es que nuestro Proyecto de Vida debe construirse con bases sólidas y lógicas y propender a la realización de nuestros ideales como seres individuales y sociales que somos, así pues por diferentes que puedan llegar a ser nuestras expectativas de vida frente a las de otros seres humanos, siempre tenemos un fin común que se resume en la palabra: "Vivir". Vivir a plenitud alcanzando una a una las metas fijadas, vivir conscientemente cada una de las experiencias que se nos presentan en la cotidianidad, vivir una a una las emociones positivas y sentir las negativas, sin que por ello desfallezca vuestro ímpetu y nuestro objetivo principal, vivir con intensidad cada uno de los retos que se nos presentan a diario, saliendo victoriosos en cada pequeña batalla, aun si lo que obtuvimos no era lo esperado e idealizado, pero logrando obtener enseñanza en esos momentos de éxito o fracaso según como lo interpretemos, afrontar todas las situaciones que día a día se nos presentan, con la valentía requerida para siempre seguir adelante en la "persecución de nuestro ideal: LA CALIDAD DE VIDA".

La comunicación se puede traducir en convivencia, paz y armonía, al utilizarla como puente para expresar ideas que promuevan el respeto, la cordialidad y los buenos modales; como dice el dicho "la decencia no pelea con nadie". Lo que se debe tener en cuenta es ser lo más asertivo posible, para poder y saber decir las cosas en el momento adecuado, a la persona indicada y en el tono correcto.

La comunicación lleva al disfrute de las relaciones humanas, porque en la medida que nos comunicamos adecuada y asertivamente, podemos compartir experiencias enriquecedoras, que nos permitirán conocer a otras personas y crear lazos de amistad y afectivos, que se traduzcan en buenos momentos y nuevas experiencias para compartir, de acuerdo con nuestras aptitudes, habilidades y afinidades.

El compromiso social que debemos adquirir, está encaminado a rescatar los valores que sustentan la convivencia en familia y en sociedad. Hace falta en 
especial, volver a inculcar, rescatar y practicar los valores y principios religiosos: la fe, la bondad, la misericordia, el perdón. Adicionalmente, debemos llevar todos nuestros esfuerzos a rescatar la tolerancia, la solidaridad, la compasión, el verdadero amor filial y la empatía. Si no empezamos a comprender que todos los seres humanos cometemos errores, pero tenemos derecho a ser escuchados, perdonados y a darnos la oportunidad de cambio, esta sociedad seguirá en crisis, hasta llegar al caos y la autodestrucción; sin embargo, estos cambios deben comenzar en cada uno de nosotros como individuos, como pedagogos, como docentes, como maestros y, lo que es más importante, como seres humanos que educamos con el ejemplo, de lo contrario con qué autoridad moral podremos exigir dichos comportamientos?

De lo anterior podemos concluir que con algunos pequeños cambios en nuestras actitudes y comportamientos, podemos generar un gran cambio no solo a nivel personal, sino a nivel social, ya que todo cambio en el individuo se ve reflejado en su entorno social.

El control de las emociones no es una tarea fácil, lo que debemos hacer es que estas emociones jueguen a nuestro favor; la clave está en utilizarlas de forma inteligente, para que trabajen en beneficio propio, de modo que nos ayuden a controlar nuestra conducta y nuestros pensamientos, con el objetivo de obtener mejores resultados. Gracias a la plasticidad de nuestro sistema nervioso podemos aprender, apropiarnos de ciertas habilidades emocionales que brinden en el plano personal un rendimiento más óptimo y mejores relaciones interpersonales y por consecuencia, una mejor calidad de vida, ya que no entramos en conflicto con nosotros mismos ni con el otro.

De nuestra calidad de vida se deriva la salud y bienestar integral que necesitamos mientras estemos vivos.

Algunas de las recomendaciones que podemos ofrecer para descubrir, crear y mantener los buenos hábitos que promuevan el fortalecimiento de la Inteligencia emocional son:

Aprender a escuchar antes de reaccionar.

Cuando nos tomamos el tiempo de analizar la información que estamos recibiendo y realizamos una retroalimentación adecuada, podemos entender los motivos por los cuales se produjo una situación determinada y podemos tomar los correctivos necesarios y adecuados para su manejo.

Practicar la empatía, es decir ponernos en los zapatos del otro para poder entenderlo desde su propia realidad.

Cuando pensamos en el otro y nos preocupamos por su situación, podemos llegar a apoyarlo sintiendo lo que él sentiría o pensaría ante determinada situación, además podremos evitar su sufrimiento a través de la comprensión y la solidaridad.

No personalizar todo lo que nos dicen, ni pensar que es una agresión directa a nuestro ser.

Cuando alguien nos dice algo que nos suene ofensivo o desagradable, no debemos tomarlo tan a pecho, ni considerarlo como algo desafiante, simplemente escuchamos y le damos la valoración que consideremos a la justa medida, sin necesidad de dejarnos alterar negativamente por ello.

Dar un manejo total y consciente a nuestras emociones a través de la práctica continúa.

Debemos aprender a conocernos y entendernos a nosotros mismos para poder a conocer y entender a los demás. Cuando logramos el autoconocimiento, somos capaces de lograr el autocontrol, pues tenemos conciencia de todo aquello que nos afecta, o nos causa malestar; así mismo lo que nos pone de buen humor y nos alegra la existencia, lo podemos manejar a nuestro favor. Con la práctica continua de las acciones y pensamientos positivos, logramos tener control sobre los momentos negativos y por lo tanto sobre nuestras reacciones ante dichas emociones. 
Practicar el valor que Dios nos enseñó con su ejemplo: El Perdón.

Si Dios fue capaz de enviarnos a su hijo para que se sacrificara por el perdón de nuestros pecados, ¿por qué a veces se nos hace tan difícil perdonar a alguien, que según nuestra percepción, nos ha ofendido? Generalmente, nosotros mismos nos llenamos de ideas y pensamientos imperdonables, que se repiten una y otra vez en nuestra mente, quitándonos la paz y tranquilidad que deberíamos tener, sin darnos cuenta que el culpar a otros de lo que sentimos y hacemos es darle el poder para que manipule nuestra vida a su antojo, cuando la solución está en nuestras manos y es tan fácil acceder a ella.

Autocontrolándonos a través de la respiración y la relajación.

Cuando experimentamos un estado de ansiedad o angustia, o cuando sentimos ira, impotencia o cualquier emoción negativa, podemos controlarla respirando pausada y tranquilamente y evocando recuerdos gratos que nos den paz interior y tranquilidad. También los paseos por el campo escuchando los sonidos de la naturaleza o apreciando las maravillas que Dios nos regaló, pueden ser un gran ejercicio de relajación.

Practicar el valor de la tolerancia y el entendimiento a nuestros semejantes.

Si entendemos que todos los seres humanos, pensamos, actuamos y reaccionamos de forma diferente ante situaciones similares, lograremos entender que no hay verdades absolutas y que lo que para mí es evidente y no tiene duda, tal vez para los demás no lo sea tanto. Además, ante las actuaciones erradas de los demás debemos dar el beneficio de la duda y no juzgarlos por lo que consideramos fue una falta pensada y premeditada.

Practicar los mandamientos que Dios nos enseñó, en especial: Amar a Dios sobre todas las cosas y Amar al prójimo como a nosotros mismos.

Cuando vemos a quienes nos rodean como nuestros hermanos, podemos servirles y colaborarles de co- razón y así mismo brindarles nuestro apoyo incondicional y nuestra solidaridad sin juzgamientos ni rotulaciones que eviten comportarnos amablemente con ellos. Si los tratamos con la misma consideración y respeto con el que nos gustaría ser tratados, mejoraríamos sustancialmente su calidad de vida y de paso la nuestra, pues evitaríamos conflictos innecesarios que lo único que hacen es desgastarnos física, psicológica y moralmente.

Ser asertivos al momento de comunicar nuestras inconformidades, haciéndolo directamente con quien corresponde, en el momento justo, en la justa medida y por la causa justa.

No se trata de guardar y almacenar todas nuestras inconformidades o puntos de vista diferentes, sino de manifestarlos de la mejor manera posible, sin alterarnos ni dejarnos llevar por los impulsos que en la mayoría de los casos nos dejan peor de lo que estábamos y a veces hasta terminamos diciendo o haciendo algo de lo que después nos arrepentimos, pero cuyas consecuencias pueden ser desastrosas.

Preocupándonos por el bienestar de quienes están a nuestro alrededor, haciéndoles la vida más amable y no obstaculizando sus realizaciones personales.

Si logramos alegrarnos por el triunfo ajeno, alejando todo síntoma de envidia o rechazo por las capacidades, adquisiciones o logros obtenidos por nuestros semejantes; y adicionalmente damos gracias a Dios por todas las bendiciones recibidas, lograremos nuestra propia tranquilidad y bienestar al aceptar que otros también merecen recibir sus recompensas.

\section{REFERENCIAS BIBLIOGRÁFICAS}

Armstrong, T. (2001). Inteligencias Múltiples. Cómo descubrirlas y estimularlas en sus hijos. Bogotá (Colombia). Editorial Norma, S.A.

Cf. Frans B. M. de Waal. (2009). La empatía en los animales. Mente y Cerebro. Edited By Richard-Byrne.

Diccionario de la Real Academia Española, Avance de la $23^{a}$ edición, cociente intelectual. 
Gardner (1983). Inteligencias Múltiples. Boston M.A. Harvard Business School Press.

Goleman, D. (1995). Inteligencia Emocional. Por qué es más importante que el cociente intelectual: Barcelona (España). Ediciones B, S.A.
López E. y Arango T. (2002). Inteligencia Emocional. Aprendiendo y creciendo juntos: Bogotá (Colombia). Ediciones Gamma S.A.

Oxford English Dictionary. Actualization (2005). Edited By Oxford University Press. 